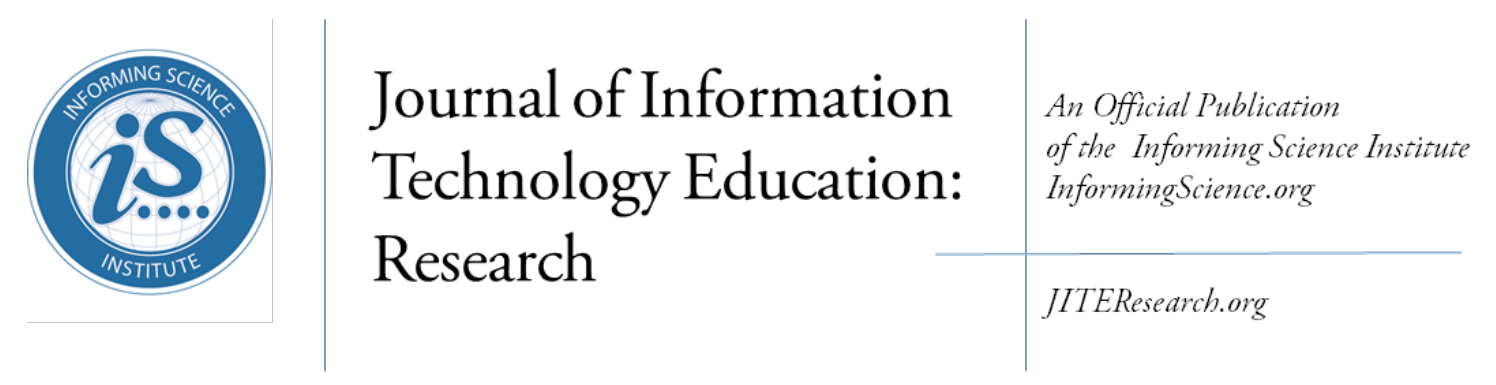

Volume 16, 2017

\title{
LEARNING Foreign LANGUAgES USING MOBILE APPLICATIONS
}

\begin{tabular}{lll}
\hline Ruti Gafni* & $\begin{array}{l}\text { The Academic College of Tel Aviv Yaffo, } \\
\text { Tel Aviv, Israel }\end{array}$ & rutigafn@mta.ac.il \\
Dafni Biran Achituv & $\begin{array}{l}\text { The Academic College of Tel Aviv Yaffo, } \\
\text { Tel Aviv, Israel }\end{array}$ & dafniba@gmail.com \\
Gila Joyce Rachmani & $\begin{array}{l}\text { The Academic College of Tel Aviv Yaffo, } \\
\text { Tel Aviv, Israel }\end{array}$ & gilarachmani93@gmail.com
\end{tabular}

* Corresponding author

ABSTRACT

Aim/Purpose This study examines how the use of a Mobile Assisted Language Learning (MALL) application influences the learners' attitudes towards the process of learning, and more specifically in voluntary and mandatory environments.

Background Mobile devices and applications, which have become an integral part of our lives, are used for different purposes, including educational objectives. Among others, they are used in the process of foreign language acquisition. The use of a MALL application to learn foreign languages has advantages and drawbacks, which are important to understand, in order to achieve better learning results, while improving the enjoyment of the process.

Methodology The study population included people who participated in a foreign language course and used Duolingo application on a mobile device in parallel. One group consisted of high school pupils, who were obliged to use the application and filled in before and after questionnaires. The other group consisted of people who took face-to-face courses, and chose to use the same Duolingo application voluntarily, in order to assist their studies. The second group answered another questionnaire tailored to more experienced users. The findings were analyzed using IBM SPSS version 22, and a model was examined with Partial Least Squares Structural Equation Modeling.

Contribution This paper helps to understand the perceived advantages and drawbacks of using a MALL application by students both in mandatory and voluntary environments.

Findings Most of the participants found the MALL Duolingo application enhanced the learning process. The gamification characteristics, ease of use, ubiquity and self-

Accepted by Editor Lynn Jeffrey | Received: April 29, 2017 | Revised: June 26, July 15, September 2, 2017 | Accepted: September 6, 2017.

Cite as: Gafni, R., Achituv, D. B., \& Rachmani, G. J. (2017). Learning foreign languages using mobile applications. Journal of Information Technology Education: Research, 16, 301-317. Retrieved from http://www.informingscience.org/Publications/3855

(CC BY-NC 4.0) This article is licensed to you under a Creative Commons Attribution-NonCommercial 4.0 International License. When you copy and redistribute this paper in full or in part, you need to provide proper attribution to it to ensure that others can later locate this work (and to ensure that others do not accuse you of plagiarism). You may (and we encourage you to) adapt, remix, transform, and build upon the material for any non-commercial purposes. This license does not permit you to use this material for commercial purposes. 
learning facilities had a stimulating effect on the process of learning, and contributed to the willingness to continue using the application and to recommend it to others. However, some statistically significant differences were found between the groups, referring to the characteristics of the application, among them ubiquity, lack of human feedback and simplicity of use.

Recommendations The research findings can contribute to both teachers and students who confor Practitioners duct and participate in foreign language courses, by helping them examine the possibility of combining mobile learning with a traditional face-to-face course. Moreover, the findings can assist developers of mobile learning applications, in order to include gamification options in the process of learning.

Recommendation Researchers in the fields of mobile applications and m-learning need to underfor Researchers stand the factors enhancing the learning process, in order to develop the next generations of m-learning applications.

Impact on Society Mobile devices have become an accessory that almost every person in the world uses. Its ubiquitous characteristics allow using it everywhere and anytime. This is an opportunity to facilitate education to people all around the world. Gamification of m-learning applications can promote and encourage the use of these applications.

Future Research Further examination is needed in different cultures, in order to understand if the findings are universal.

Keywords mobile applications, foreign languages, MALL, mobile assisted language learning, m-learning, gamification

\section{INTRODUCTION}

The biblical story, "Tower of Babel", describes the process of extinction of a common language and the creation of new and different languages, which caused misunderstanding and an inability to communicate with each other. Today, there are thousands of spoken languages; therefore, people learn foreign languages in order to be able to communicate with people from other places and to enrich their knowledge.

Mobile devices and applications, which have become an integral part of our lives, are used for different purposes, including educational objectives. Therefore, they have a significant role in the process of foreign language acquisition. The purpose of this study is to examine the influence of using applications in mobile devices as a tool assisting language learning, on the learners' attitude towards the learning process and satisfaction with the process. The study was conducted in two different populations. The first one are people that decided to use the application of their own free will, regardless of this study, while studying in a foreign language face-to-face course. The second population was composed of the students of a foreign language course in high school, who were asked to use the mobile application.

The research findings may assist foreign languages teachers and students who participate in foreign languages courses. The conclusions of this study can help them examine the possibility of combining mobile learning, with a traditional face-to-face course. Moreover, the findings can assist developers of mobile learning applications, in order to include gamification options in the process of learning.

The remainder of this paper is organized as follows. First a theoretical background of mobile assisted language learning, its evolution, the use of gamification and the advantages and disadvantages of using this kind of assistance when studying a new language is provided. Then, the research questions are explained. The methodology section describes the manner this study was conducted. Thereafter, the results are displayed, and finally the discussion and conclusions are presented. 
Gafni, Achituv, \& Rachmani

\section{THEORETICAL BACKGROUND}

\section{MOBILE ASSISTED LANGUAGE LEARNING}

Mobile learning (m-learning), is the ability to learn independently of place and time, it is wireless and ubiquitous (Alexander, 2004; Chen, 2013) using supporting mobile-wireless information systems and mobile technologies. M-learning has been found to be effective in improving educational outcomes because it improves the opportunity to gain education and to promote learning, which is personalized, collaborative and ubiquitous and where the learner is at the center. The supporting technology in m-learning includes any kind of handheld mobile small devices such as cell phones, smartphones, personal digital assistants, pads, tablets, etc. (Viberg \& Gronlund, 2013, Gafni, 2009). The main features of mobile learning are accessibility, immediacy and interactivity (Bachore, 2015). Accessibility refers to the extent to which every learner owns a mobile device. Currently, many learners, worldwide, possess this technology. For example, according to the Pew Research Center, in 2015, $68 \%$ of American adults own a smartphone, and $45 \%$ have a tablet (Anderson, 2015). Moreover, $86 \%$ of the younger adults (aged 18-29) have a smartphone. According to Radicati (2015), in 2014, the number of worldwide mobile users reached over 5.6 billion, and, by the end of 2018 , the number of worldwide mobile users is expected to increase to over 6.2 billion. According to research performed by the Pew Research Center, smartphone ownership rates in emerging and developing nations are rising at an extraordinary rate, climbing from a median of $21 \%$ in 2013 to $37 \%$ in 2015 (Poushter, 2016). It is important to remember, however, that Internet access rates in the emerging and developing world still trail those of advanced economies. In addition, where technology is available, learners can be connected and they can extend their opportunity to learn ubiquitously. Mobile learning creates an interactive learning environment, using different kinds of applications, which are available on mobile devices.

The Common European Framework determines six levels of proficiency in a language (Council of Europe, 2001). Each level includes the following skills: listening comprehension, reading, writing and speaking. There are three domains, which should be considered when characterizing mobile assisted language learning: (1) physical, (2) pedagogical, and (3) psychosocial domains (Bachore, 2015). Physical issues are related to screen size, methods of inputting, processor speed, storage capacity, and battery life. Most of these issues were characterized as drawbacks in past studies (see, for example, Gafni, 2009). Pedagogical issues refer to ensuring that tasks are suited to the affordances of the devices used. Psychosocial issues refer to the social environment. While desktops or laptops are used mainly for work or study purposes, mobile devices have been designed for personal or social purposes. However, having the possibility to connect through social networks, using their mobile device, to people knowing and speaking the target language can enhance interaction, reading, writing and speaking, in that language.

Any process in which a learner uses a computer and as a result improves language use, is considered as a Computer Assisted Language Learning (CALL) (Jarvis \& Archileos, 2013). The term CALL became established in language education in the early 1980s. At first, the area was limited to desktop computers with a few basic mechanical software programs. However, during the years, this field has grown to include applications, online blogs and vlogs (video blogs), virtual learning environments, online courses, and more. The development of mobile devices, their widespread availability, and their common use, has led to the creation of a new field called Mobile Assisted Language Learning (MALL). MALL is used in formal and informal learning of foreign languages (Chen, 2013). MALL differs from CALL because of its personal use, the use of portable devices that enable new ways of learning, emphasis on continuity or spontaneity of access across different context of use. MALL is a relatively new research area, despite the fact that people have been using personal portable devices for some time (Gafni, 2009). The main difference in MALL to traditional face-to-face language learning is the mobility the former affords, in addition to the possibilities of spatial and time shifts yielding increased learning opportunities. Another distinguishing feature of MALL is connectivity. 
Through the 3G Internet access, which has over 69\% of the world's population coverage in 2015 (ITU, 2015), and Wi-Fi, modern mobile devices provide language learners with opportunities to be involved in meaningful real-context interactions, which are often lacking in traditional learning environments. Thus, language learning has changed its characteristics, no longer limited to an individualbased single method of learning, but has evolved to a collaborative multi-method learning experience. Empirical studies have found that the use of mobile devices and applications as tools of learning foreign language is efficient for learners. For example, Azar and Nasiri (2014) found that mobile learning improved students listening comprehension. Alemi, Anani and Lari (2012) investigated the effect of sending a short message (SMS) containing foreign words, their meaning and example sentences, on vocabulary learning and retention. Their results showed that, in the short term, there were no significant differences between learning vocabulary via SMS and using a dictionary. However, in the long term, the vocabulary learned via SMS, was better remembered than the vocabulary learned from the dictionary.

\section{LEARNING THROUGH GAMIFICATION}

Deterding, Dixon, Khaled and Nacke (2011) defined gamification as the "use of game design elements in non-game Contexts". In order to encourage users to perform tedious but substantial tasks, the activity is wrapped with an enjoyable context. The following studies describe examples of gamification used in the language acquisition area and the researchers' conclusions. Alemi (2010) found that word games have a positive effect on vocabulary development as part of second language acquisition. Meihami, Varmaghani and Meihami (2013) strengthened these findings, arguing that CALL and especially simulation games have a significant effect on better English vocabulary and pronunciation learning. Their findings were based on an experiment during which sailors and mariners were divided into 2 groups. Participants of the experimental group learned vocabulary and pronunciation through simulator games while the control group learned the same material but in a traditional way through the teacher. Both groups took a test after 45 days of learning and results showed that those who used simulation games had significantly higher achievement levels in both vocabulary and pronunciation. Similar results were found in a study, which took place in Iran (Aghlara \& Tamjid, 2011). Results of an experimental group and a control group, containing 20 girls each, all 6 to 7 years old, were compared after a period of 45 days of learning. The experimental group, which used a computer game for English vocabulary acquisition, was much more successful. The conclusions of that study also determined that the use of computer games for language learning reduces the stress involved in the process and makes learning more enjoyable. Moreover, educational computer games have other positive effects on learners (Grimley, Green, Nilsen, Thompson, \& Tomes, 2011). Students that used computer games for learning were more alert, active, felt more involved and experienced the activity as more challenging than students who participated in traditional lectures. A study that examined students from two Spanish universities found that the students felt that Duolingo was easy to use, helpful in studying and enjoyable (Munday, 2016). It seemed that because of its convenience, the students liked it more than a regular book based homework. Other factors that influenced these attitudes are the mobile access to the application, the variety of activities and the gamifications aspects.

\section{ATTITUDES, ADVANTAGES AND DISADVANTAGES OF MALL}

Mobile Assisted Language Learning have several advantages and disadvantages (Krivoruchko, Raissova, Makarikhina, Yergazinova, \& Kazhmuratova, 2015).

On the one hand, a mobile device is portable, readily available and relatively cheap. Hence, learning through mobile applications provides easy access to learning materials, individual place and time of study, immediate feedback, and self-testing. Moreover, it is an attractive and dynamic process, which increases students' motivation and encourages them to study. Viberg and Gronlund (2013) conducted a study with Chinese and Swedish students that investigated if age, gender or cultural factors affect the attitudes toward mobile technology use in foreign language learning. They found that the attitudes related to technology culture (e.g. mobility, individualism, etc.) was more important for stu- 
dents' attitudes and behavior than attitudes related to national, traditional and local culture. Chen (2013) investigated how Chinese students use tablet computers to learn a foreign language, especially outside of class. It was found that tablets are ideal tools for creating an interactive, collaborative and ubiquitous environment for language learning, and that students have a generally favorable attitude towards the usability, effectiveness, and satisfaction of tablet computers for MALL. In a study conducted in Taiwan in which 58 second-year's college students participated, all of whom took an English course and had minimal experience of using mobile devices for m-learning (Yang, 2012). The results showed that the students felt that m-learning offered them the chance to acquire more information than in a traditional class, and that it supported collaborative and ubiquitous learning. Many students indicated that the use of mobile devices along with task-based assignments enhanced their motivation and they had much more fun in English learning. A study investigating learners' attitude towards the effectiveness of MALL on their listening comprehension, found that Iranian students studying English, considered it a useful learning process (Azar \& Nasiri, 2014). The effectiveness came from the ease of access to learning materials, which can be done ubiquitously, anywhere and anytime. Steel (2012) examined students', perspectives of the benefits of using mobile applications for foreign language learning in an Australian university, finding that the ability to practice a language anywhere and anytime allowed the flexibility and convenience they needed in their busy lifestyle. The students also deemed this kind of learning to be useful, especially for vocabulary acquisition, reading, writing and grammar.

On the other hand, the small screen and keypad, and the dependence on the Internet can be problematic for some learners (Viberg \& Gronlund, 2013; Gafni, 2008). Moreover, there are users who want to study in a quiet environment, which makes public surroundings less attractive.

\section{GENDER DIFFERENCES IN LEARNERS'ATTITUDE}

Much research was done about first language acquisition focusing on gender differences. Most of these demonstrated better female performance, especially in verbal abilities and differences in second language acquisition also (Pavlenko, Blackledge, Piller, \& Teutsch-Dwyer, 2001; Larsen-Freeman \&

Long, 2014). On the other hand, although technology is used by both genders, there is a lack of clear understanding about whether there are gender differences in adoption and use of technology (Poushter, 2016). Cai, Fan and Do (2017) performed a meta-analysis of 50 studies, and found that, in general, males showed a better attitude toward technology use than females, especially in aspects of belief (e.g., believing in the societal usefulness of technology) and self-efficacy (e.g., self-confidence in one's ability to learn and use technology effectively). However, female attitudes toward technology use were still positive, rather than negative. Yang (2012) conducted research in Taiwan, and found no significant differences between male participants and female participants' attitudes on MALL. Interviews that were carried out showed that male students were more accustomed to using mobile devices for English learning outside the class than female students, who perceived the mobile device mainly as an entertainment facility. Unlike those findings, Viberg and Gronlund (2013) in their Chinese and Swedish students' study, found strong positive correlations between gender and attitudes toward MALL. They found that female students are more positive toward the use of mobile devices in language learning.

\section{VOLUNTARINESS OF INFORMATION SYSTEMS USE}

Petter, DeLone, and McLean (2013) define voluntary use as the degree to which users are not required to use the system. They state that voluntariness has been found as a moderator variable rather than a predictor of the information system success. Dečman (2015) using the Unified Theory of Acceptance and Use of Technology (UTAUT) as a model to evaluate the prediction of use and satisfaction of a mandatory e-learning system, found that social influence has a significant influence on behavioral intention to use in mandatory, but not in voluntary settings. Wu and Lederer (2009) found that using technology in a mandatory environment does not predict behavioral intention to use it; therefore, there is no need to encourage the users by extrinsic motivations. If a company enforces 
employees undertaking mandatory e-learning, extrinsic motivation tends to be muted or attenuated. Lee (2006) found that in order to increase the overall adoption of an e-learning system by students, mandatory use is necessary.

\section{THE RESEARCH QUESTIONS}

This study examines how Mobile Assisted Language Learning influences the learners' attitudes to the process of learning. More specifically, how the language learning process through the mobile Duolingo application is perceived by the students, and which attributes they find useful or disturbing. In order to understand these influences, four research questions were posed.

Research Question 1: Which aspects of using a MALL application, specifically mobile Duolingo, in the learning process, are perceived as useful by the students, and which are perceived as disturbing? To what extent do these perceptions change after using this mobile application?

In prior studies (Chen, 2013) found that the use of mobile technologies as a language learning tool was perceived by students to have high usability, be simple and easy to work with, and as providing great effectiveness to improve foreign learning performance. It has been found that technology enhances the satisfaction and the desire to learn. Moreover, students found their autonomy and learning ubiquity useful (Viberg \& Gronlund, 2013). Krivoruchko et al. (2015) found that the advantages of MALL are portability, availability, accessibility, ubiquity, immediate feedback, and self-knowledge testing. Viberg and Gronlund (2013) and Gafni $(2008,2009)$ found that the disadvantages of using mobile devices for learning purposes are the small screen and keypad of mobile devices, the dependence on the Internet and the noisy public learning environment.

Research Question 2: What are the differences in perceptions of students that choose voluntarily to study using Duolingo as a mobile assisted language-learning tool, and those who were obliged to do so?

Studies about adoption of technologies, which are used voluntarily or mandatory, found that mandatory environments do not need extrinsic motivations to use the system, while in voluntary use these motivations are needed (Wu \& Lederer, 2009). Petter et al. (2013) found that voluntariness is not a predictor for using the system.

Research Question 3: Are there any gender differences in students' attitudes towards a MALL application?

Prior research about the differences in gender perceptions and attitudes towards technology in education showed inconsistent findings (Cai et al., 2017). Those findings indicated that males still hold more favorable attitudes to technology use than females, but such differences would be characterized as small effect sizes.

Research Question 4: What causes learners to continue using a MALL application, and even recommend it to others?

A model to define the factors affecting the future usage of the application by students, and the willingness to recommend it to others will be determined from information gathered in the previous research questions. The variables to be included are derived from the perceptions of the students using a MALL application, advantages and disadvantages of using the mobile Duolingo application, the voluntariness of the usage and the gender.

\section{METHODOLOGY}

The study population includes people who participated in foreign language courses and used the MALL Duolingo on a mobile device in parallel during the same period. 
The Duolingo application is a free learning languages application, created by Luis von Ahn and Severin Hacker (von Ahn, 2013) in November 2011, and it has more than 30 million registered users (Munday, 2016). It offers several languages for English speakers as well as others for non-English speakers and has versions for desktop and mobile. The application is used to leverage different skills: reading, writing, hearing, and understanding, translating and speaking. The most common activities to achieve these are: writing a word after seeing a picture that represents it, translating a sentence from the foreign language to the native language, translating a sentence from the native language to the foreign one, writing a sentence after hearing it, pronouncing a sentence, matching pairs of words. Duolingo includes several subjects, such as plurals, modal verbs, animals, food, which are further divided into several lessons that are adapted to the learner's level. Each subject is represented by a node that changes its color from grey, indicating that the subject has not been started, to gold, indicating the optimal control within the subject. The gold color can "turn" back to another color if the algorithm of Duolingo determines that some of the vocabulary has been forgotten. The learning method is based on gamification, which encourages students to keep learning and to enhance their efforts. The students are rewarded with points, according to their success, and they "compete" against friends to see who has the highest amount of points.

The research was divided into two parts:

(1) The A-Questionnaire: This questionnaire was distributed to people learning in foreign language courses, who, in parallel, also used the Duolingo application. This population used the MALL application voluntarily. The questionnaire was distributed using Facebook groups of students who participated in foreign language courses. Some Facebook groups were addressed, and from these groups, students who use Duolingo in parallel with a face-to-face course were asked to answer the questionnaire. The A-Questionnaire was anonymous.

This questionnaire included 23 questions. The first questions were demographic questions about gender, age and level of knowledge of different languages. Two questions filtered the participants who did not meet the criteria of studying in a face-to-face course and using the Duolingo MALL application in parallel. The next questions examined the students' attitudes towards the usage of MALL and specifically Duolingo for language learning. Some of the questions included a Likert scale, some were multiple-answer questions and others were single-answer questions.

(2) A two-phase questionnaire, which was distributed to pupils in the ninth grade of a high school in Israel, who were studying French. The mother tongue of the pupils was not English, they learnt English in both elementary and high school, and in addition, they were required to take a French course in high school as a new foreign language. The pupils had no experience at all in using any kind of MALL. This two-phase questionnaire included identification of the pupils, in order to match the before and after parts.

1. The first phase, Before-Questionnaire: The pupils answered a questionnaire that examined their perceived attitude towards the use of applications on mobile devices to learn French, without knowing any application of this kind. Afterwards, they received a short explanation about Duolingo. The Before-Questionnaire was composed of 17 questions. It included general questions about gender and level of knowledge of different languages, and some filter questions that checked if the participant used learning language applications before. Participants who had experienced some kind of MALL before, were excluded from the results. The remaining questions examined the participants' perceived attitudes towards using a MALL application in French learning, some of them in a form of statements which needed to be ranked (Likert scale 0-4), and others were multiple-choice questions. 
2. The pupils had to study for one week, with the Duolingo application, on tablets or smartphones. The application reminded learners and encouraged them to use it by sending alerts and emails to the pupils.

3. The last phase, the After-Questionnaire: The pupils answered a second questionnaire that examined their attitudes towards the use of mobile devices to learn French, and Duolingo in particular, after experiencing it.

The two-phase questionnaires enabled the examination of changes in the pupil's perceived attitudes after their first experiences with Duolingo. Both questionnaires had identical questions about the pupils' perceived attitudes, to be answered before and after using the MALL application. A few extra questions were added to the After Questionnaire, to evaluate the frequency of use during the experience week, their satisfaction of the experience, and their intention to continue using the application and to recommend it to friends.

Pupils who did not use the Duolingo application were omitted from the sample.

Questions for the three questionnaires (A, Before and After questionnaires), were taken (and translated to the local language), from validated questionnaires in previous research conducted by Yang (2012), Chen (2013), Munday (2016) and from the study of Viberg and Gronlund (2013).

The results were analyzed using IBM SPSS version 22. The model was further examined with Partial Least Squares Structural Equation Modeling (PLS SEM) (Gefen, Straub, \& Rigdon, 2011; Hair, Ringle, \& Sarstedt, 2011; Ringle, Sarstedt, \& Straub, 2012) with SmartPLS 2.0 (M3) Beta (Ringle, Wende, \& Will, 2005).

\section{RESULTS}

The A-Questionnaire was answered by 66 people, but the responses of 8 were omitted since they did not meet the requirement of using Duolingo in parallel of the face to face course. The BeforeQuestionnaire and After-Questionnaire were answered by 41 high school pupils who participated in the course. Responses of 10 of them were omitted because they did not use the Duolingo application at all.

All the participants in both samples lived in the same country. They were all learning a foreign language course, and they used the Duolingo mobile application as an additional assistant to regular classes. The participants were asked about their knowledge of languages. They reported their prior languages knowledge; including the level of proficiency, (0: do not know at all; 4: mother tongue level). Table 1 summarizes the demographic descriptive statistics of the participants. Although the age of the two groups are different, both belong to the same generation, the "Y Generation", who are familiar with the use of digital devices (Gafni \& Geri, 2013).

The respondents were asked about their perceptions of using Duolingo as a MALL application. These questions were asked in all three questionnaires. In the A-Questionnaire the participants had already experienced using the application. In the Before-Questionnaire these were perceptions before using it, and in the After-Questionnaire the participants filled the same questions as in the BeforeQuestionnaire, but this time after using the application.

The participants had to rate each statement from 0: 'not at all' to 4: 'very much'. With these statements, two constructs were defined: 'Ease of Use' and 'Learning Enhancement'. The 'Ease of Use' construct was composed using the statements dealing with easy to use, easy to learn, simple to use and the reversed statement of boring. The construct 'Learning Enhancement' was composed using the statements dealing with helping learning, stimulating learning, enjoying learning, improving learning and making learning more interesting. Principal Component Analysis with Varimax rotation was used to examine construct validity. The constructs were defined and checked separately for each of the questionnaires, giving similar high validity. Table 2 specifies for those items the means and stand- 
ard deviation and the constructs' definition, according to the reliability, measured by Cronbach's alpha for each questionnaire.

Table 1. Demographic statistics

\begin{tabular}{|l|l|l|}
\hline & A-Questionnaire & Before and After-Questionnaires \\
\hline Number of participants & 66 & 41 \\
\hline Number of valid answers & 58 & 31 \\
\hline Gender & Male 35 (60.3\%) & Male 10 $(32.3 \%)$ \\
& Female 23(39.7\%) & Female 21 $(67.7 \%)$ \\
\hline Age & $14-18: 4(6.9 \%)$ & $14-18: 31(100 \%)$ \\
& $19-23: 13(22.4 \%)$ & \\
& $24-28: 22(37.9 \%)$ & \\
& $29-33: 13(22.4 \%)$ & \\
\hline $\begin{array}{l}\text { Number of languages } \\
\text { (knowing very well or }\end{array}$ & 1 Language: $2(3.4 \%)$ & 1 Language: $6(19.4 \%)$ \\
mother tongue) & 2 Languages: $41(70.7 \%)$ & 2 Languages: $24(77.4 \%)$ \\
\hline Willingness to use & voluntary & 3 Languages: $1(3.2 \%)$ \\
\hline
\end{tabular}

Table 2. Perceptions - constructs definition

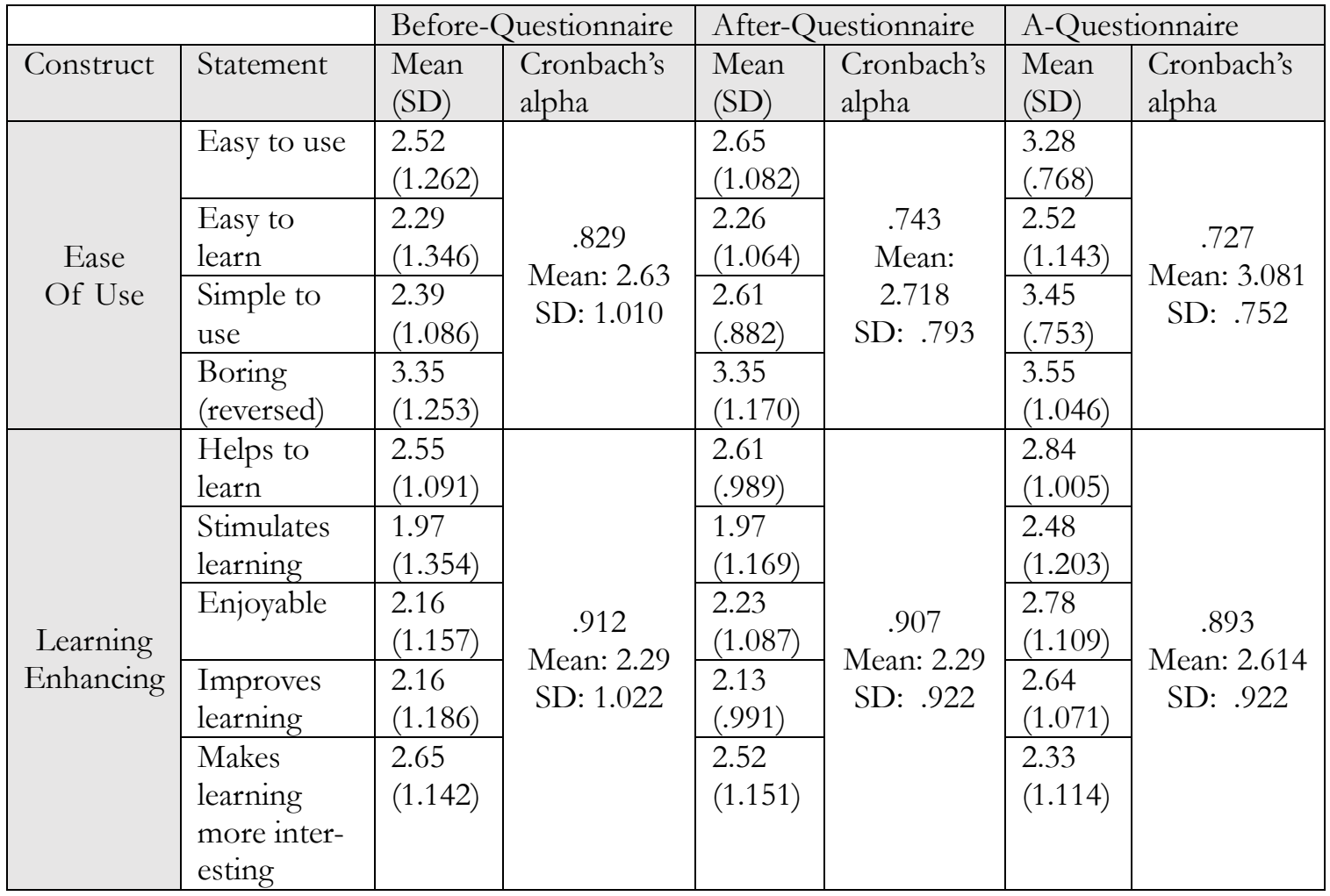

SmartPLS, which is a SEM analysis tool, was used to define three latent variables; that is, theoretical constructs that cannot be observed or measured directly (such as beliefs, intentions, and feelings), and can only be measured indirectly through indicators (Gefen et al., 2011). (1) Gamification was 
constructed from the following indicators: Enjoyable (load: 0.884), Makes learning more interesting (load: 0.848), Stimulates Learning (load: 0.814) and Satisfying (load: 0.910). (2) Ubiquitous use was composed of the following indicators: Ubiquity (load: 0.739), Control of Place and Time (load: 0.739) and Independent Learning (load: 0.700). (3) Self-Learning was constructed from: SelfExamination (load: 0.947) and Immediate Feedback (load: 0.753).

In order to define the advantages and disadvantages of using Duolingo as a MALL application, the respondents had to check a list of characteristics ( 0 : do not agree, 1: agree). The characteristics that were mainly found as disadvantages were: Temptations and distractions, No human Feedback, and Internet dependence. The characteristics that were mainly found as advantages were: Portable, Easy access to learning materials, Ubiquitous, Adjusted to the student, Control over place and time of study, Learning independence and Self-testing.

The perceptions of the pupils, before they had experienced the mobile Duolingo application (the Before-Questionnaire) and after experiencing it (the After-Questionnaire), were examined, to measure whether these perceptions had been changed. T-tests were performed for all questions. Table 3 presents only the characteristics, which were statistically significant after experiencing the use of the mobile Duolingo. As it can be seen, pupils were concerned about being disturbed by the distractions in the mobile device, or by the noisy environment, but they discovered that these factors are not an impediment to the learning process. Moreover, they originally thought that the absence of a human teacher was an issue with this kind of learning, but they found it not be problematic. The characteristic of self-testing was found less beneficial than expected before the experience.

Table 3. Statistical significant changes after usage experience

\begin{tabular}{|l|l|l|l|}
\hline Characteristic & $\mathrm{t}$ & Before mean (SD) & After mean (SD) \\
\hline $\begin{array}{l}\text { Temptations and distractions due } \\
\text { to the mobile device }\end{array}$ & $4.139^{* *}$ & $.65(.087)$ & $.23(.076)$ \\
\hline Noisy environment & $2.108^{*}$ & $.19(.072)$ & $.06(.045)$ \\
\hline No human feedback & $2.516^{*}$ & $.74(.08)$ & $.45(.091)$ \\
\hline Self-testing & $2.278^{*}$ & $.77(.076)$ & $.52(.091)$ \\
\hline$* * p<0.01,{ }^{*} p<0.5$ & \multicolumn{4}{l}{} \\
\hline
\end{tabular}

The next step was to examine the differences in attitudes towards Duolingo MALL application, between those who used the MALL voluntarily (the A-Questionnaire) and those who were required to use it (the After-Questionnaire). Factors with statistically significant differences are shown in Table 4. It can be seen that students who use the application voluntarily found it friendlier to use (Easy to use, Simple) and they were more satisfied (Enjoyable, Improves learning) than students who were required to use it. The former liked the portability and ubiquity of Duolingo; however, they were very concerned about the noisy environment. Moreover, they did not need to follow friends and compare their progress, and they were less bothered about having a human feedback.

In order to examine whether there are gender differences in perceptions, the A-Questionnaire and the After-Questionnaire were explored with an independent T-Test. Moreover, they were examined to see if there were differences based on the voluntariness of the usage. The results are shown in Table 5. It can be seen that, in the whole sample together, male students found the use of the MALL application easier and simpler to use and less boring than female students did. Moreover, the female participants found ubiquity less important and were less concerned about the dependence on the Internet. Examining the voluntary sample, the only characteristic that was found to be significantly different was the ubiquity, where male students evaluated as more important than female did, the same that was found in the whole sample together. In the mandatory sample, male students found the application easier than female students did, but female students found the dependence on the Internet more disturbing, and self-examination as an advantage of using the MALL application, more than the male students did. 
Table 4. Statistical differences between voluntary and mandatory usage

\begin{tabular}{|l|l|l|l|}
\hline Characteristic & $\mathrm{t}$ & $\begin{array}{l}\text { Mandatory mean } \\
(\mathrm{SD})\end{array}$ & $\begin{array}{l}\text { Voluntary mean } \\
(\mathrm{SD})\end{array}$ \\
\hline Easy to use & $-3.190^{*}$ & $2.65(1.082)$ & $3.28(.768)$ \\
\hline Simple to use & $-4.693^{* *}$ & $2.61(.882)$ & $3.45(.753)$ \\
\hline Enjoyable & $-2.245^{*}$ & $2.23(1.087)$ & $2.78(1.109)$ \\
\hline Improves learning & $-2.190^{*}$ & $2.13(.991)$ & $2.64(1.071)$ \\
\hline Allows comparing to friends & $2.918^{*}$ & $.29(.461)$ & $.07(.256)$ \\
\hline Small screen & $2.984^{*}$ & $.35(.486)$ & $.10(.307)$ \\
\hline Noisy environment & $-2.098^{*}$ & $.06(.250)$ & $.24(.432)$ \\
\hline No human feedback & $4.751^{* *}$ & $.45(.506)$ & $.07(.256)$ \\
\hline Ubiquitous & $-5.168^{* *}$ & $.55(.506)$ & $.95(.223)$ \\
\hline Portable & $-2.055^{*}$ & $.55(.506)$ & $.78(.423)$ \\
\hline$* * p<0.01, * p<0.5$ & & &
\end{tabular}

Table 5. Statistical differences between male and female

\begin{tabular}{|l|l|l|l|}
\hline Characteristic & $\mathrm{t}$ & Male mean (SD) & Female mean (SD) \\
\hline The whole sample & & & \\
\hline Easy to use & $-2.954^{*}$ & $3.33(.739)$ & $2.77(1.03)$ \\
\hline Simple to use & $-3.230^{*}$ & $3.44(.755)$ & $2.86(.930)$ \\
\hline Boring & $2.028^{*}$ & $1.29(.920)$ & $1.75(1.203)$ \\
\hline Internet dependence & $2.788^{*}$ & $.435(.074)$ & $.505(.076)$ \\
\hline Ubiquitous & $-2.527^{*}$ & $.288(.043)$ & $.462(.070)$ \\
\hline Voluntary usage & & & \\
\hline Ubiquitous & $2.251^{*}$ & $1.00(.000)$ & $.87(.344)$ \\
\hline Mandatory usage & & & \\
\hline Easy to use & $2.077^{*}$ & $3.20(.919)$ & $2.28(1.071)$ \\
\hline Internet dependence & $-3.007^{*}$ & $.10(.316)$ & $.62(.498)$ \\
\hline Self-examination & $-2.613^{*}$ & $.20(.422)$ & $.67(.483)$ \\
\hline$* * p<0.01,{ }^{*} p<0.5$ & & &
\end{tabular}

Finally, all information was examined to justify the worth of continuing to use the MALL application and to recommend it to others. To get the specific model to define the factors affecting these two actions, SmartPLS was used (Gefen et al., 2011; Hair et al., 2011; Ringle et al., 2012). Figure 1 shows the model defined, with the relevant path coefficients presented on the connections. The rectangular shapes are the observed indicators. The oval shapes are the independent (Gender and Voluntariness) and dependent variables (all the others), which are the latent variables. Gender influenced perceptions of both Frequency and Ease of Use. Voluntariness influenced Frequency. Other extrinsic variables, such as Age and number of High Proficiency in Languages, had no statistical effect. The coefficient of determination, $\mathrm{R}^{2}$, is 0.644 for the perceptions about Ease of Use variable. This means that the two variables (Gender and Gamification) moderately explain $64.4 \%$ of the variance in Ease of Use. Male participants found the application easier to use than female students did. Voluntariness (participants who were obliged to use the application used it more frequently), Ubiquity use, and Gender variables explain 10.6\% of the Frequency variable. Ease of Use, Frequency of use and SelfLearning variables (and all the variables explaining them) explain $63.1 \%$ of Learning Enhancing. Recommendation to use Duolingo was explained by all the predicting variables together by $31 \%$, and aim to use Duolingo MALL application again, was explained by all the predicting variables together by $10 \%$. 


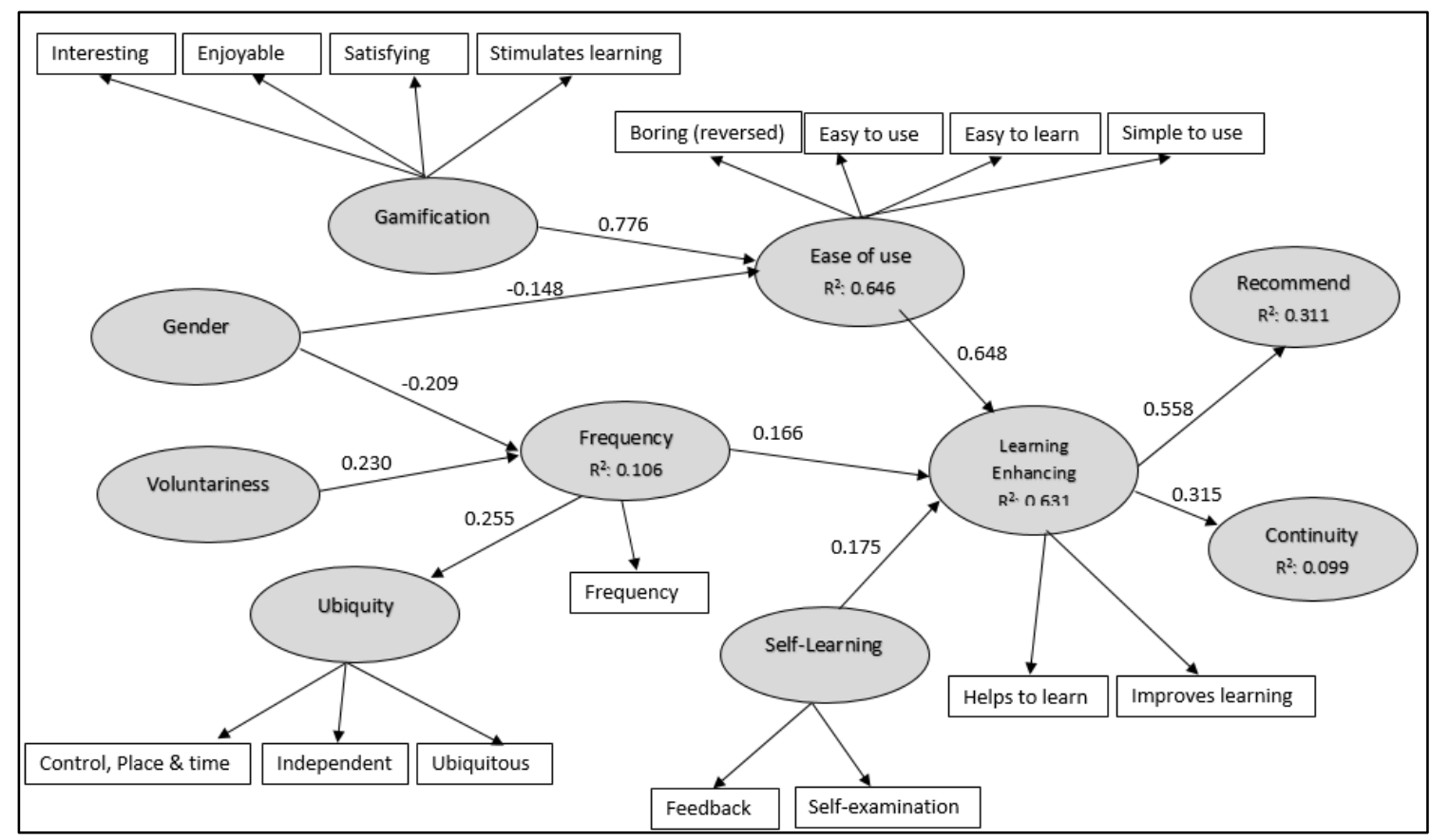

Figure 1: Factors affecting recommendation and continuity of usage

\section{DISCUSSION}

The results suggest that users of the Duolingo MALL application find the mobile learning assistant useful. It is easy to use the application, and learning with its assistance is enhanced. These results are concur with prior studies (Chen, 2013; Viberg \& Gronlund, 2013; Yang, 2012).

The findings of this study provide support for the notion that the use of MALL applications, specifically Duolingo, has advantages and drawbacks. The advantages can be summarized as:

(1) The ubiquity of MALL - its ability to work on a portable device, which can be used anytime and anywhere according to the needs of the user and available free time - is an advantage, as found in previous studies (Krivoruchko et al., 2015; Viberg \& Gronlund, 2013; Azar \& Nasiri, 2014; Steel, 2012). This ability also influences users to use the application more frequently (as shown in Figure 1), as the application is available to the student whenever he or she has a spare moment. Today's students, who are part of the $\mathrm{Y}$ generation, are continually connected with their mobile devices. Therefore, in any opportunity when they have free time, they can use this application.

(2) The characteristics that can be considered to enable self-learning are advantageous when using a MALL application, as found in previous studies (Viberg \& Gronlund, 2013; Bachore, 2015). Learning processes and materials that are adapted to the student and easily accessed, learning independence, the ability for self-testing and the immediate feedback that the application provides, makes the use of Duolingo very worthwhile.

(3) The gaming aspect of the application stimulates learning, makes the tasks more enjoyable and interesting, as can be seen in Figure 1. This enjoyable interaction influences the user's perception of the application as being easier to use, concurring with Munday's (2016) findings.

On the other hand, some negatives were found:

(1) The Internet dependence - This was a surprising finding. About half of the participants perceived Internet dependence to be a disadvantage. In the past, when studies referred to the 
annoyance of Internet connections (Gafni, 2008), the Internet was not available ubiquitously, was not stable, and the price of connectivity was very high. More recently, connection facilities have become relatively cheap and more readily available (ITU, 2015). Nevertheless, people still perceived this as a disadvantage. A possible explanation is that some of the participants used tablets instead of smartphones. Smartphones enable access to the Internet via Wi-Fi, as well as via the phone (3G connection), whereas this may not be the case for some tablets that are dependent solely on the availability of Wi-Fi.

(2) A noisy environment was also defined as only a small disadvantage, compared to prior studies (Gafni, 2008), in which this was one of the barriers to adoption of mobile devices. This maybe because people have got used to operating mobile devices everywhere, even in noisy public areas, like in the street, buses, trains, places that previously were not perceived as suitable places to concentrate on performing a task through a computer or application.

(3) One of the problems people encountered was using the mobile device not only as a learning device, but also as a system that provides entertainment, social networking, information, and more. Therefore, the distractions and temptations they have while using the device (calls, SMS, notifications, etc.) had the potential to disturb their concentration when learning.

The characteristics of the small device, including a small screen and/or a small keyboard that had found in past studies (Gafni, 2008) as being very annoying, were not a major complaint in this study. This may be because previous studies were conducted in the early adoption period of mobile devices (2007-2008) when smartphones had just been released and people were not used to working with such small devices. With the growing use of these devices (Anderson, 2015), people seem to have become accustomed to using them.

According to Bachore (2015), one of the characteristics of the mobile learning is its potential for social networking. Pupils perceived networking with other pupils, the comparison of progress and their achievements as somehow important, while the voluntary users hardly ever referred to this possibility at all. The reason may be that, in the mandatory sample, the class all learnt together, while the participants of the voluntary sample were gathered from different courses, and were not part of their normal social network, so they did not have any interest in comparing or communicating with other students.

Some perceptions changed after experiencing the use of the MALL application. Students found some perceived disadvantages as being less disturbing than they had first thought. This can maybe be explained by the concern of coping with a new technology. For example, the noisy environment had a minimal impact on their studies. The participants were worried that the distractions on their mobile devices would be disruptive, but they found it less bothersome. The pupils thought that the absence of human feedback would reduce their learning outcomes, but they found it was not necessarily so.

There are a number of reasons for the use of two different populations in the study. First, this is an explorative study about the use of Duolingo as a MALL, and the results suggest further studies. Second, the main difference between the groups was the voluntariness of the usage of Duolingo, which was explored in this study. It was interesting to explore differences and similarities in the perceptions of the two groups. Some differences in the perceptions were found between these two samples, as shown in Table 4. The voluntary sample gave higher ranks to the advantages of the application. They found Duolingo easier and simpler to use, more enjoyable, with greater improvement in the learning process. On one hand, the ubiquity of the usage, because of the portability of the device and the use of the application anywhere and anytime was a great advantage for them. On the other hand, the noisy environment was found slightly more disturbing. The participants in the voluntary sample did not complain about the absence of a human feedback, and the ability to manage a network of students and compare achievements was not interesting for them. 
Some of these findings can be explained by the environment. The mandatory sample was a class learning together at school. It is possible that they used Duolingo mostly in class, and less afterwards, thus, the ubiquity was not so important. Moreover, they were accustomed to having a human teacher in class, so working with machine feedback could feel a bit strange for these high school students who were not used to it. The other differences in perceptions can be explained by the voluntariness of the usage. People who are obliged to use a technology find it less helpful than those who choose it. Voluntariness to use requires a number of decisions. First, the person has to decide to use an application for the task. Second, they must decide which application, because for each task there may be more than one option. Third, the person has to decide which device to use. For example, Duolingo is available for workstations, tablets and smartphones. After making so many decisions, people tend to be satisfied with their choice.

The comparison between the perceptions of male and female students to using a MALL application was interesting. For most of the characteristics, no statistical differences were found. However, male students found the application to be simpler and easier to use, as well as less boring, and they were less bothered about ubiquity and Internet dependence. This was surprising, because the study was performed in a developed country where both males and females have a high technology orientation. Perhaps, male participants have more experience with computer games, and thus these kinds of applications seemed simpler to them. However, the results concur with the interview part of Yang's study (2012), which found that males used the MALL technology outside the classroom more frequently than females.

The most important factor that affects the students' decisions to continue using Duolingo and to recommend it to others is the learning enhancing capabilities. The factors associated with learning enhancements are ease of use, frequency of use and self-learning facilities. When an application is easy to use, the people are more willing to use it and therefore they will achieve the usefulness the application can contribute. The same applies to frequency of use. The more the application is used, the more the students practice the new language, and the better they perceive the usefulness of the MALL application. Moreover, the third factor affecting the learning enhancement is self-learning, which is composed of the immediate feedback received by the application and the possibility to selfexamination.

Ease of use is affected by gender and gamification. The study found that male students (in both groups together) perceived the use of Duolingo easier. Nevertheless, the main factor is gamification. When people need to perform tasks repeatedly in a boring environment, they will cease rapidly. When these boring and repeated tasks are wrapped in an enjoyable activity, which is the basis of gamification, the users will persist in trying to get more points or rewards.

Frequency of use is influenced by voluntariness (users who were obliged to use Duolingo used the application more frequently) and by ubiquity. The situation that the device with the application was available to the user anywhere and anytime, maintaining the status and the level the user reached, stimulates the user to keep working on it, each time he or she has a spare moment. Moreover, the frequency of use is influenced by gender, in general, in both groups together (male students used the application more frequently than female students did).

\section{CONCLUSIONS}

The purpose of this exploratory study was to examine the influence of using applications in mobile devices as a tool assisting language learning, on the learners' attitude about the learning process. Most of the students found the Duolingo MALL application an enhancement to the learning process.

The most important factors that affected the learning process were the ease of use, the gamification of the application and the ubiquity of the device and application. These factors had a stimulating effect on the process of learning and the willingness to continue using it and recommend to others. 
The research findings can assist foreign languages teachers and students who participate in foreign language courses, by helping them examine the possibility of combining mobile learning, with a traditional face-to-face course. Teachers can enhance the gamification side of the MALL, by encouraging pupils to compete between themselves, and to use the facilities of connections between the pupils in order to organize groups to work together, thus, making the learning process more enjoyable and more significant.

Moreover, the findings can assist developers of mobile learning applications, in order to include gamification options in the process of learning. Gamification is a very important feature in performing repeating tasks, which can be very boring. Learning a new language can be so. Therefore, playing with the words and competing versus others can be very encouraging, thus, stimulating the learning process.

Mobile devices have become an accessory that almost every person in the world uses. Its ubiquitous characteristics allow using it everywhere and anytime. This is a great opportunity to facilitate education to people all around the world. Gamification of m-learning applications can promote and encourage the use of these applications.

\section{LIMITATIONS AND FURTHER RESEARCH}

The samples in this study are relatively small, and the reason was the difficulty to find people attending a foreign language course, and concurrently using the Duolingo MALL application. It is important therefore to test these conclusions in a larger study. Additionally, the time the pupils in high school experienced the application was very short. A longer period may have provided different or additional insights. Another limitation is that all learners were from the same country, with high exposure to technology. The findings need to be verified in more diverse countries the advantages and drawbacks of using a MALL application are different. In this study, the focus was in understanding the perceived attitudes of the students. The learning outcomes were not examined.

\section{REFERENCES}

Aghlara, L., \& Tamjid, N. H. (2011). The effect of digital games on Iranian children's vocabulary retention in foreign language acquisition. Procedia-Social and Behavioral Sciences, 29, 552-560.

Alemi, M. (2010). Educational games as a vehicle to teaching vocabulary. Modern Journal of Applied Linguistics, 2(6), 425-438.

Alemi, M., Anani S. R., \& Lari, Z. (2012). Successful learning of academic word list via MALL: Mobile assisted language learning. International Education Study Journal, 5(6), 99-109.

Alexander, B. (2004). Going nomadic: Mobile learning in higher education. EDUCAUSE Review, 39(5), 28-35.

Anderson, M. (2015). Technology device ownership: 2015. Retrieved from http://www.pewinternet.org/2015/10/29/technology-device-ownership-2015/

Azar, A. S., \& Nasiri, H. (2014). Learners' attitudes toward the effectiveness of mobile assisted language learning (MALL) in L2 listening comprehension. Procedia Social and Behavioral Sciences, 98, 1836-1843.

Bachore, M. M. (2015). Language learning through mobile technologies: An opportunity for language learners and teachers. Journal of Education and Practice, 6, 50-53.

Cai, Z., Fan, X., \& Du, J. (2017). Gender and attitudes toward technology use: A meta-analysis. Computers and Education, 105, 1-13.

Chen, X. B. (2013). Tablets for informal language learning: Student usage and attitudes. Language Learning and Technology, 17(1), 20-36.

Council of Europe (2001). Common European framework of reference for languages: Learning, teaching, assessment. Cambridge: Cambridge University Press. 
Dečman, M. (2015). Modeling the acceptance of e-learning in mandatory environments of higher education: The influence of previous education and gender. Computers in Human Behavior, 49, 272-281.

Deterding, S., Dixon, D., Khaled, R., \& Nacke, L. (2011). From game design elements to gamefulness: Defining "gamification". Proceedings of the 15th International Academic MindTrek Conference: Envisioning Future Media Environments, 9-15. ACM.

Gafni, R. (2008). Framework for quality metrics in mobile-wireless information systems. Interdisciplinary Journal of Information, Knowledge, and Management, 3, 23-38. Retrieved from http://www.ijikm.org/Volume3/IJIKMv3p023-038Gafni358.pdf

Gafni, R. (2009). Measuring quality of M-Learning Systems. In R. Guy (Ed.) The evolution of mobile teaching and learning. Santa Rosa, CA: Informing Science Press. Retrieved from https://books.google.co.il/books?hl=iw\&lr=\&id=Cz5SCEaHNAMC\&oi=fnd\&pg=PA211\&ots=U44fT j

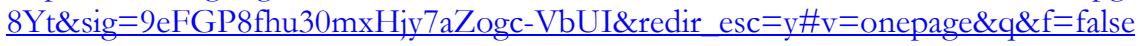

Gafni, R., \& Geri, N. (2013). Generation Y versus Generation X: Differences in smartphone adaption. Proceedings of the CHAIS Conference on Instructional Technologies Research: Learning in the Technological Era, Raanana, Israel. Retrieved from https://pdfs.semanticscholar.org/f54b/6b37cb2bc98dd58be8e03ae1ff762a31c6ea.pdf

Gefen, D., Straub, D.W., and Rigdon, E.E. (2011). An update and extension to SEM guidelines for administrative and social science research. MIS Quarterly, 35(2), iii-xiv.

Grimley, M., Green, R., Nilsen, T., Thompson, D., \& Tomes, R. (2011). Using computer games for instruction: The student experience. Active Learning in Higher Education, 12(1), 45-56.

Hair, J. F., Ringle, C.M., and Sarstedt, M. (2011). PLS-SEM: Indeed a silver bullet. Journal of Marketing Theory and Practice, 19(2), 139-152.

ITU (2015). The world in 2015 - ICT facts and figures. ITU Telecommunication Development Bureau. Retrieved from https://www.itu.int/en/ITU-D/Statistics/Documents/facts/ICTFactsFigures2015.pdf

Jarvis, H., \& Archileos, M. (2013). From computer assisted language learning to mobile assisted language learning. ESL-EJ, 16(4), 1-18.

Krivoruchko, V. K., Raissova, A. B., Makarikhina, I. M., Yergazinova, G. D., \& Kazhmuratova, B. R. (2015). Mobile-assisted learning as a condition for effective development of engineering students' foreign language competence. International Education Studies, 8(7), 158-168.

Larsen-Freeman, D., \& Long, M. H. (2014). An introduction to second language acquisition research. Abingdon, UK: Routledge.

Lee, Y. C. (2006). An empirical investigation into factors influencing the adoption of an e-learning system. Online Information Review, 30(5), 517-541.

Meihami, B., Varmaghani, Z., \& Meihami, H. (2013). CALL in the Form of Simulation Games: Teaching English Vocabulary and Pronunciation through Sims. International Letters of Social and Humanistic Sciences, 8, 5765 .

Munday, P. (2016). The case for using Duolingo as part of the language classroom experience. Revista Iberoamericana de Educación a Distancia, 19, 83-101.

Pavlenko, A., Blackledge, A., Piller, I., \& Teutsch-Dwyer, M. (Eds.). (2001). Multilingualism, second language learning, and gender (Vol. 6). Berlin: Walter de Gruyter.

Petter, S., DeLone, W., \& McLean, E. R. (2013). Information systems success: The quest for the independent variables. Journal of Management Information Systems, 29(4), 7-62.

Poushter, J. (2016). Smartphone ownership and internet usage continues to climb in emerging economies. Retrieved from http://www.pewglobal.org/2016/02/22/smartphone-ownership-and-internet-usage-continues-to-climbin-emerging-economies/

Radicati, S. (2015). Mobile statistics report, 2014-2018. Palo Alto, CA: The Radicati Group, Inc. Retrieved from http://www.radicati.com/wp/wp-content/uploads/2014/01/Mobile-Statistics-Report-2014-2018Executive-Summary.pdf 
Ringle, C.M., Sarstedt, M., \& Straub, D. (2012). A critical look at the use of PLS-SEM. MIS Quarterly, 36(1), iiixiv.

Ringle, C. M., Wende, S., \& Will, S. (2005). SmartPLS 2.0 (M3) Beta. Hamburg.

Steel, C. H. (2012). Fitting learning into life: Language students' perspectives on benefits of using mobile apps. In M. Brown, M. Hartnett, and T. Stewart (Eds.). Ascilite 2012: Future challenges, sustainable futures (pp.875880). Wellington, New Zealand: Massey University.

Viberg, O., \& Gronlund, A. (2013). Cross-cultural analysis of users' attitudes toward the use of mobile devices in second and foreign language learning in higher education: A case from Sweden and China. Computers and Education, 69, 169-180.

von Ahn, L. (2013). Duolingo: Learn a language for free while helping to translate the web. Proceedings of the 2013 International Conference on Intelligent User Interfaces (pp. 1-2). New York: ACM.

Wu, J., \& Lederer, A. (2009). A meta-analysis of the role of environment-based voluntariness in information technology acceptance. MIS Quarterly, 33(2), 419-432.

Yang, S.-H. (2012). Exploring college student's attitudes and self-efficacy of mobile learning. Turkish Online Journal of Educational Technology, 11, 148-154.

\section{BIOGRAPHIES}

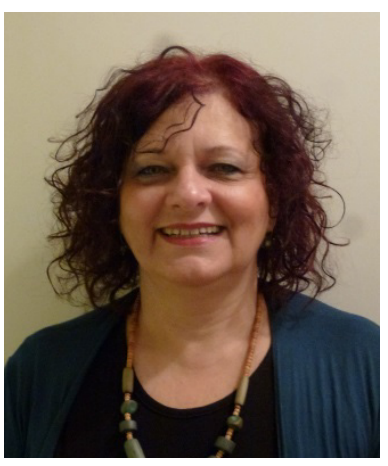

Ruti Gafni is the Head of the Information Systems BSc program at The Academic College of Tel Aviv Yaffo. She holds a PhD from Bar-Ilan University, Israel (in the Business Administration School), focusing on Information Systems, an M.Sc. from Tel Aviv University and a BA (Cum Laude) in Economics and Computer Science from Bar-Ilan University. She has more than 40 years of practical experience as Project Manager and Analyst of information systems. She also teaches in the Management and Economics MBA program at the Open University of Israel.

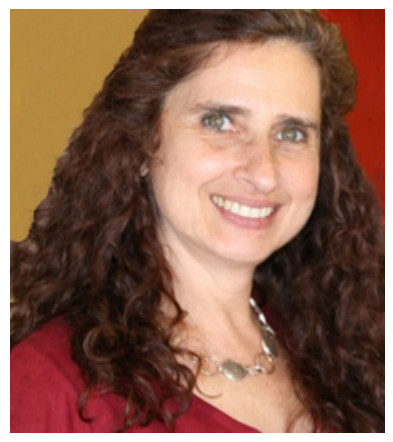

Dafni Biran Achituv teaches in the Information Systems BSc program at The Academic College of Tel Aviv Yaffo. She holds an MA in Organizational Consulting and Development (summa cum laude) and a BA in Mathematics, Computer Science and Psychology. She has over 30 years of practical experience as a Project Manager and Information Systems Analyst.

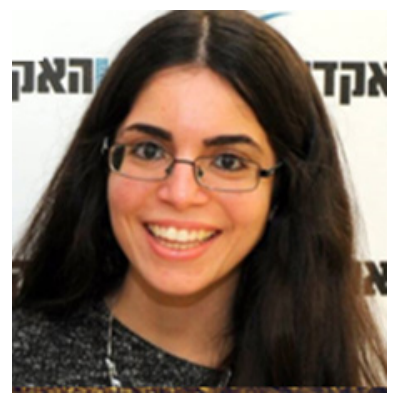

Gila Joyce Rachmani is a third year student in the Information Systems BSc program at The Academic College of Tel Aviv Yaffo. She was acknowledged twice in the President's list of the academy. 